\title{
NOTES
}

\section{Late-Phase Expression of a Murine Cytomegalovirus Immediate- Early Antigen Recognized by Cytolytic T Lymphocytes}

\author{
MATTHIAS J. REDDEHASE, MATHIAS R. FIBI, GÜNTHER M. KEIL, AND ULRICH H. KOSZINOWSKI* \\ Federal Research Centre for Virus Diseases of Animals, D-7400 Tübingen, Federal Republic of Germany
}

Received 2 May 1986/Accepted 11 August 1986

\begin{abstract}
The cloned murine cytolytic T-lymphocyte line IE1-IL and several sublines detect a murine cytomegalovirus immediate-early (IE) membrane determinant in conjunction with $\mathbf{L}^{d}$ class $I$ major histocompatibility glycoprotein. The lines retained cytolytic activity, strict antigen specificity, and self-restriction even when adapted to long-term, antigen-independent growth in the presence of interleukin-2 only (M. J. Reddehase; H.-J. Bühring, and U. H. Koszinowski, J. Virol. 57:408-412). These attributes allowed us to use IE1-IL as a stable, monospecific probe for tracing the expression of the IE membrane antigen throughout the viral replication cycle. Presentation of the antigen at the cell membrane proved to be most effective when expression of IE genes in infected mouse embryo fibroblasts was selectively enhanced by consecutive cycloheximideactinomycin D treatment, whereas without enhancement high numbers of IE1-IL cytolytic T lymphocytes were required to demonstrate the antigen in the IE phase. In the early phase of infection when IE genes were no longer transcribed, cytolysis was not observed, although IE proteins were detectable in the nuclei of the infected cells. Without application of inhibitors IE membrane antigen expression was most prominent during the late phase of infection. Reinitiation of transcription from the genomic region encoding the major IE protein (pp89) and de novo synthesis of pp89 correlated with this reexpression of the IE membrane antigen.
\end{abstract}

Members of the herpesvirus family such as herpes simplex viruses, varicella zoster virus, Epstein-Barr virus, and cytomegalovirus (CMV) establish latency in the immunocompetent host, but can cause fatal disease in cases of immunosuppression (17). Murine CMV (MCMV) infection has proven a convenient model to investigate aspects of herpesvirus latency $(2,6)$, recurrency $(10,15)$, pathogenesis $(3,4,25,27)$, and immunity $(20,22)$ in the natural host.

The replication cycle of herpesviruses can be divided into three phases of coordinately regulated expression of genes: the immediate-early (IE; $\alpha$ ) phase, the early $(\beta)$ phase, and the late $(\gamma)$ phase $(9,11,31)$. A result not anticipated by previous studies with other herpesviruses was the finding that IE genes, the first viral genes transcribed after infection of permissive cells, not only encode regulatory intracellular proteins essential for viral replication, but also specify a membrane antigen which serves as a target structure for MCMV-specific cytolytic T lymphocytes (CTL) $(23,24)$. The predominant IE gene product of MCMV, a trans-activating 89,000 -dalton (89K) phosphoprotein (pp89) located mainly in the nucleus of the infected cell, is encoded by gene iel, which is controlled by a strong transcriptional enhancer (5, 12, 14). Although MCMV virions are composed of many different structural polypeptides including six glycoproteins (13), most CTL sensitized during acute infection of mice were found to recognize target cells after selective enhancement of IE gene transcription (24). Beyond the IE phase, in the presence of a multitude of proteins specified by MCMV, IE membrane antigens cannot be discriminated from other antigens with a polyclonal CTL population as probe. To trace the presence of a particular IE membrane antigen throughout the viral replication cycle, we have now used the

\footnotetext{
* Corresponding author.
}

cloned CTL line IE1-IL (Lyt-2.2 $2^{+}, \mathrm{L} 3 T^{-}, \mathrm{L}^{\mathrm{d}}$ restricted) that defines the antigenic determinant IE1 (21). Data demonstrate that expression of target antigen is mainly a latephase event that correlates with reexpression of the major IE gene.

As anticipated by previous studies $(21,23,24)$, the IE membrane antigen was detected when the expression of IE genes was enhanced by infection in the presence of cycloheximide. After a period of selective transcription, cycloheximide was replaced by actinomycin D (ActD) to allow translation of accumulated IE transcripts and to prevent transcription of early-phase genes (Fig. 1, column A, closed circles). This protocol also excluded induction of cellular antigens by pp89-mediated transcriptional activation. The antigen was not detectable when the same amount of virus, inactivated by UV light, was used for mock infection (column A, squares). This control ensured that the antigen recognized by clone IE1 was not a virion structural antigen or a cellular antigen induced by virion protein, by inhibitor treatment, or by an interaction of both. With another CTL clone, clone $\mathrm{S} 1$, a structural antigen can be detected on this type of target cell (21).

Consistent with previous observations using polyclonal CTL (23), lysis was barely detectable during the IE phase when the expression of IE genes was not enhanced (Fig. 1, column B). At the multiplicity of infection used throughout this experiment, 2 PFU of MCMV per cell, 80 to $90 \%$ of fibroblasts displayed intranuclear pp89 during all phases as identified with monoclonal antibody MCMV-6/58/1 [immunoglobulin G2b (k)] by indirect immunofluorescence. It should be noted that the observed low level of IE membrane antigen expression during the IE phase could not be elevated by raising the multiplicity of infection (data not shown). In contrast, lysis was more pronounced, in particular when 
effector/target cell ratios are considered, during the late phase of infection (column $\mathrm{C}$ ). This finding showed for the first time that IE membrane antigen is expressed in an amount sufficient for CTL effector function under conditions not influenced by application of inhibitors. Similar to the synthesis of most $\gamma$ gene products, the presentation of the IE1 epitope during the late phase could be prevented by infection in the presence of the DNA synthesis inhibitor phosphonoacetic acid (PAA; column D), while presentation of the same epitope after selective enhanced expression of IE genes was not affected by PAA (column A, open circles). These results demonstrated that the IE membrane antigen was absent during the early phase (column D) and implied that synthesis of the late-phase IE membrane antigen also dated from the late phase.

Since the IE membrane antigen is composed of the viral IE1 determinant and the cellular $\mathrm{L}^{\mathrm{d}}$ glycoprotein encoded by the major histocompatibility complex, absence or presence of the compound antigen could reflect the temporal expression of either component. The expression of $\mathrm{L}^{\mathrm{d}}$ antigen during the early and late phases of infection was therefore analyzed with an $\mathrm{L}^{\mathrm{d}}$-specific cloned CTL line referred to as $\mathrm{B} 6 \alpha \mathrm{L}^{\mathrm{d}}$ (Table 1). This line was derived by cloning from the polyclonal population of C57BL/6 anti-BALB/c CTL already used in a previous report (21). Specificity mapping for line $B 6 \alpha L^{d}$ is demonstrated in Table 1 , experiment 1 . The data shown in Table 1 , experiment 2 , revealed no significant difference in the expression of $\mathrm{L}^{\mathrm{d}}$ between noninfected fibroblasts and fibroblasts during the early or late phase of MCMV replication, but again, the IE membrane antigen was detected during the late phase. Superinfection by virions released during the late phase must be discussed as one possible explanation for this observation. Three findings, however, are not consistent with that interpretation. First, as already mentioned above, raising the multiplicity of infection under IE conditions did not result in more pronounced lysis of target cells by clone IE1. It is therefore not likely that superinfection at a later stage would cause enhanced expression of the IE membrane antigen. Second, production and release of virions in the late phase did not enhance the susceptibility of target cells to lysis by CTL clone $\mathrm{S} 1$ (not shown), although this clone has been shown previously to detect, in a dose-dependent manner, a viral structural antigen integrated into the target cell membrane from without during the penetration step of infection (21). Third, the IE membrane antigen was found to be expressed in the late phase also when significant release of infectious virus was prevented by halting late-phase transcription with ActD (Table 1). Enhanced expression of the IE membrane antigen during the late phase can therefore not be explained by superinfection.

Altogether, the viral determinant IE1 was found to be reexpressed in the late phase and thus predicted reexpression of a viral IE gene during the late phase, presumably due to transcription of the gene from an increased number of templates.

That was indeed the case, as shown by a nuclear run-on transcription assay (8) (Fig. 2A). RNA synthesized in nuclei isolated at different times during the viral replication cycle was hybridized to ie 1 sequences contained in plasmid pIE110 (14) as the specific probe and to vector pSP62 DNA (16) for control. Transcription from the genomic region represented by pIE110 was detectable during the IE phase $(\alpha ; 1$ h postinfection [p.i.]), ceased during the early phase ( $\beta$; $8 \mathrm{~h}$ p.i.), and was initiated again in the beginning late phase $\left(\gamma_{16} ; 16\right.$ h p.i.) (11), increasing with time $\left(\gamma_{24} ; 24\right.$ h p.i.).

\begin{tabular}{|c|c|c|c|}
\hline \multicolumn{4}{|c|}{ Expression of the IE 1 epitope } \\
\hline$A$ & $B$ & $C$ & $D$ \\
\hline$\alpha$ enhanced & $\alpha$ & $\alpha+\beta+\gamma$ & $\alpha+\beta$ \\
\hline CH/ACt.D & $-/$ ACt.D & & \\
\hline \pm PAA & & & PAA \\
\hline
\end{tabular}

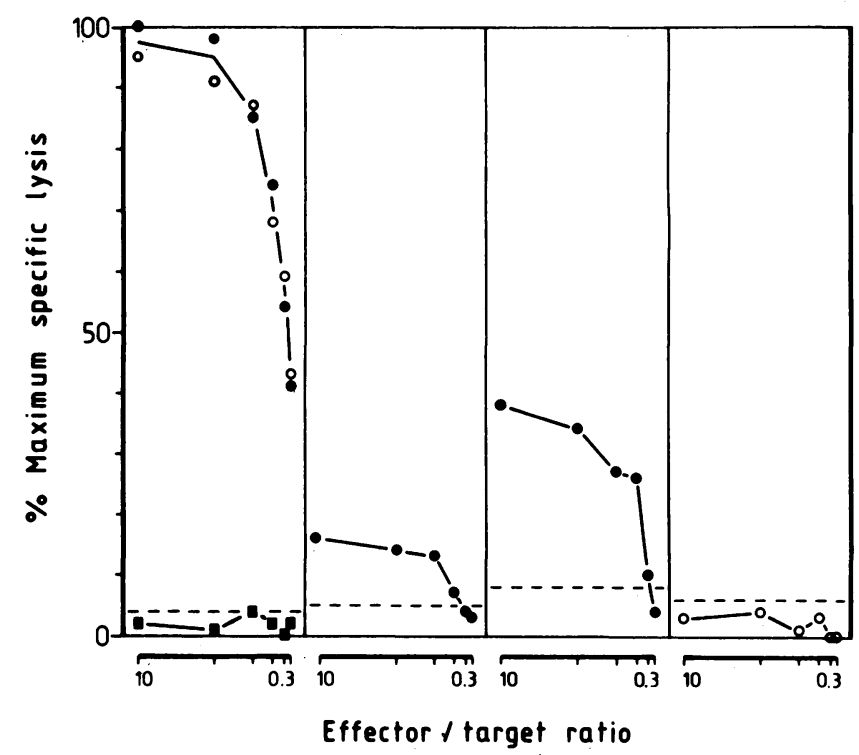

FIG. 1. Expression of the IE1 epitope during the replication cycle of MCMV. Line IE1-IL of CTL clone IE1 was used to detect the IE1 epitope. Selection and properties of this line have been described before (21). Selective, enhanced synthesis of IE proteins in target cells (column A, closed circles) was achieved by infection of tertiary mouse embryo fibroblasts [BALB/c, (KDL)] with MCMV (ATCC VR-194, Smith strain) in the presence of cycloheximide $(\mathrm{CH} ; 50 \mu \mathrm{g} / \mathrm{ml})$ that was replaced after $3 \mathrm{~h}$ by Act.D $(5 \mu \mathrm{g} / \mathrm{ml})$. In the case of nonenhanced expression of $\alpha$ genes, Act.D was added $1.5 \mathrm{~h} \mathrm{p}$.i. (column B). PAA $(250 \mu \mathrm{g} / \mathrm{ml})$ was added before infection (columns $A$ and $D$, open circles). For mock infection (column A, squares), MCMV was inactivated with UV light as described previously (24). Fibroblasts in the late phase of infection were assayed $24 \mathrm{~h}$ p.i. (column C). For each of the indicated effector/target cell ratios $\left(1,000{ }^{51} \mathrm{Cr}\right.$-labeled target cells), specific lysis was determined in six replicates in a standard $3-\mathrm{h}{ }^{51} \mathrm{Cr}$-release assay. Mean values are normalized to the maximum specific lysis observed ( $46 \%$ at effector/target cell ratio of 10 ; column A, closed circle). The dashed lines represent the upper $95 \%$ confidence limit of spontaneous lysis.

Transcription unrelated to gene $i e 1$ from a putative late gene on the opposite strand might have contributed to the signal in the run-on assay, but reexpression of gene $i e 1$ was proved by Northern blot hybridization revealing the 2.75-kilobase RNA that specifies pp89 (not shown), and immunoprecipitation of proteins biosynthetically labeled during the late phase (20 to $24 \mathrm{~h}$ p.i.) positively identified pp89 as one of the proteins synthesized in the late phase (Fig. 2B). Several late-phase polypeptides could be precipitated with immune serum, including an $89 \mathrm{~K}$ protein (lane a) that was identified as pp89. by precipitation with specific monoclonal antibody (lane b). The synthesis of late-phase proteins, including late synthesized pp89, was inhibited (lanes $c$ and d) when infection was performed in the presence of PAA. This result confirmed that viral DNA synthesis is required for reexpression of pp89.

In conclusion, although intranuclear pp89 could be de- 
TABLE 1. Expression of class I major histocompatibility complex (MHC) $\mathrm{L}^{\mathrm{d}}$ antigen during early and late phases of MCMV infection

\begin{tabular}{|c|c|c|c|c|}
\hline \multirow{2}{*}{ Target cells } & \multirow{2}{*}{$\begin{array}{l}\text { Class I MHCd } \\
\text { glycoproteins }\end{array}$} & \multirow{2}{*}{$\begin{array}{l}\text { MCMV replication } \\
\text { phase }\end{array}$} & \multicolumn{2}{|c|}{$\begin{array}{l}\text { \% Specific lysis at } \mathrm{E} / \mathrm{T} \text { ratios of } 10,5 \text {, and } 1 \text { by } \\
\text { clone: }\end{array}$} \\
\hline & & & $B 6 \alpha L^{d}$ & IE1.18-IL \\
\hline $\begin{array}{l}\text { Expt } 1^{a} \\
\text { KD2SV } \\
\text { KHTGSV } \\
\text { Ltk }^{-} \\
\text {Ltk }^{-} \text {H-2L } \\
\text { d }\end{array}$ & $\begin{array}{l}(K D L)^{d} \\
K^{d} \\
L^{d}\end{array}$ & & $\begin{array}{c}59,46,21 \\
3,0,2 \\
1,1,0 \\
43,33,22\end{array}$ & \\
\hline $\begin{array}{l}\text { Expt } 2^{b} \\
\text { MEF (-) } \\
\text { Early-MEF (2) } \\
\text { Late-MEF (2) }\end{array}$ & $\begin{array}{l}(\mathrm{KDL})^{\mathrm{d}} \\
\text { (KDL) }^{\mathrm{d}} \\
\text { (KDL) }^{\mathrm{d}}\end{array}$ & $\begin{array}{l}\text { None } \\
\alpha+\beta \\
\alpha+\beta+\gamma\end{array}$ & $\begin{array}{l}48,31,18 \\
55,39,23 \\
50,36,17\end{array}$ & $\begin{array}{r}2,2,1 \\
0,3,0 \\
11,8,4\end{array}$ \\
\hline
\end{tabular}

${ }^{a}$ Lytic activity of the cloned CTL line $B 6 \alpha L^{d}$ was determined in six replicates for the indicated effector/target cell (E/T) ratios. The mean value of specific lysis is given without normalization. Simian virus 40-transformed cell lines KD2SV (B10.D2 origin) and KHTGSV (B10.HTG origin), as well as Ltk ${ }^{-}$cells (C3H/An origin) or Ltk ${ }^{-}$cells transfected with the $\mathrm{H}-2 \mathrm{~L}^{\mathrm{d}}$ gene $\left(\mathrm{Ltk}^{-} \mathrm{H}-2 \mathrm{~L}^{\mathrm{d}} ; 19\right)$, served as target cells in a $3-\mathrm{h}{ }^{51} \mathrm{Cr}$-release assay.

${ }^{\circ}$ BALB/c mouse embryo fibroblasts (MEF) served as target cells either noninfected (-) or infected with MCMV at a multiplicity of 2 PFU per cell. In earlyMEF, PAA $(250 \mu \mathrm{g} / \mathrm{ml})$ was added before infection. In late-MEF, Act.D $(5 \mu \mathrm{g} / \mathrm{ml})$ was added $20 \mathrm{~h}$ p.i. IE1.18-IL is a subline of IE1-IL.
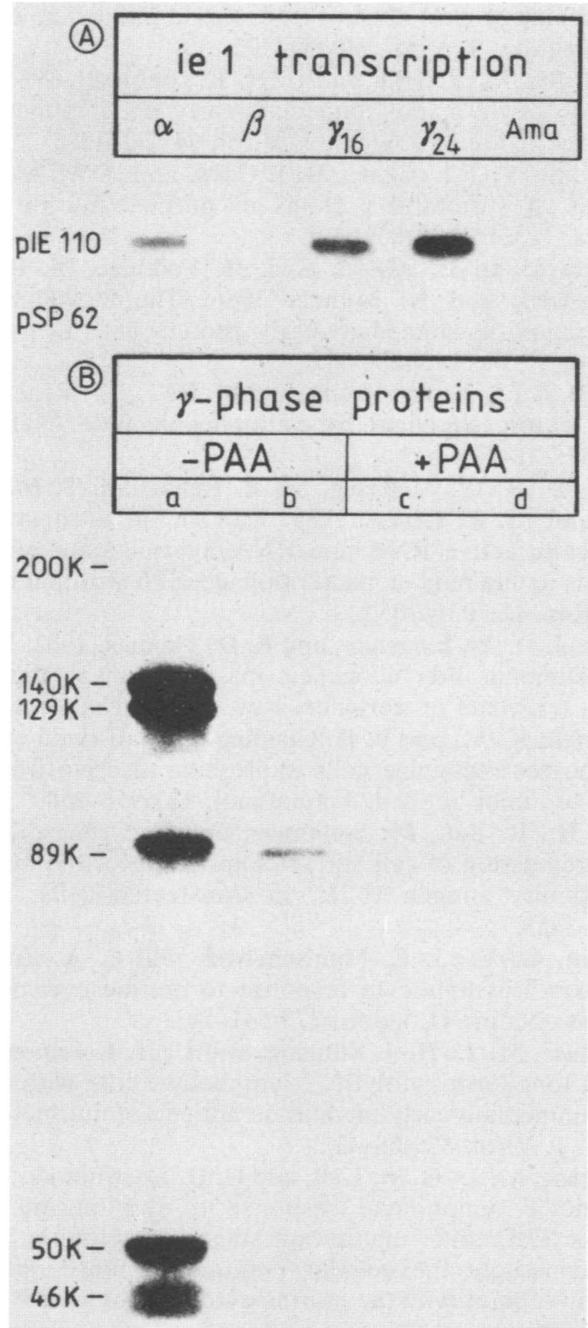

FIG. 2. Identification of $\alpha$ gene products during the late phase of MCMV replication. (A) Transcription of IE gene ie1 in nuclei isolated from $10^{7}$ infected mouse embryo fibroblasts (multiplicity of 50 PFU per cell) during different phases of MCMV replication $(\alpha, 1$ h p.i.; $\beta, 8$ h p.i.; $\gamma_{16}, 16$ h p.i.; $\gamma_{24}, 24$ h p.i.) was monitored by a nuclear run-on transcription assay performed essentially as described previously (8). Run-on transcripts labeled with $\left[\alpha-{ }^{32}\right.$ P]UTP tected with monoclonal antibody during all phases, the IE membrane antigen was not detectable during the early phase when gene ie 1 was not transcribed, but was detectable in the late phase when expression of gene ie 1 was reinitiated. These conditions have two important implications. First, presentation of IE target antigen is not correlated with intranuclear presence of the major IE protein, but rather with its synthesis, and second, infected fibroblasts are susceptible to lysis by IE-specific CTL mainly during the late phase of viral replication.

Recent findings in viral immunology converge to the conclusion that viral genes which do not code for classical cell membrane glycoproteins, but for proteins located mainly in the nucleus of the infected cell, specify immunodominant determinants recognized by CTL in conjunction with class I major histocompatibility glycoprotein. Prominent examples are the nonstructural large- $T$ antigen of the papovavirus simian virus $40(18,28)$ and the internal virion nucleoprotein of the myxovirus influenza $A(29,30,33)$. These viruses encode only a low number of proteins. Considering the high coding capacity of MCMV (7), it is remarkable that the same prin-

ciple appears to rule the CTL response to this virus $(21,23$, 24). Analysis of the organization of the MCMV IE region has revealed minor IE gene products besides the by far most abundantly synthesized pp89 encoded by gene ie1 (G. M. Keil, A. Ebeling-Keil, and U. H. Koszinowski, submitted for publication). Whether a candidate for cell membrane

for $30 \mathrm{~min}$ were hybridized at $72^{\circ} \mathrm{C}$ for $48 \mathrm{~h}$ with $1 \mathrm{pmol}$ of $i e 1$ gene plasmid pIE110 DNA (14) or vector pSP62 DNA (16) bound to nitrocellulose filters. Addition of $\alpha$-amanitin $(1 \mu \mathrm{M})$ blocked transcription in all phases, shown for late phase $\left(\gamma_{24}\right)$ nuclei (slot Ama). Consistent with the fact that MCMV does not induce shutoff of host transcription, incorporation of radioactivity was equal in all preparations. In addition, the hybridization signal to $\beta$-actin cDNA (kindly provided by B. M. Paterson, National Institutes of Health, Bethesda, Md.) remained invariant (not shown). (B) Polypeptides, labeled biosynthetically in $2 \times 10^{6}$ infected mouse embryo fibroblasts (multiplicity of $50 \mathrm{PFU}$ per cell) with $1.5 \mathrm{mCi}$ of $\left[{ }^{35} \mathrm{~S}\right]$ methionine per $\mathrm{ml}$ during the late phase ( 20 to $24 \mathrm{~h}$ p.i.), were analyzed by immunoprecipitation (12) with immune serum (lanes a and c) or IEpp89specific monoclonal antibody MCMV-6/20/1 [immunoglobulin G2a (K)] (12) (lanes b and d). PAA $(250 \mu \mathrm{g} / \mathrm{ml})$ was added before infection (lanes $\mathrm{c}$ and $\mathrm{d}$ ). 
expression is among these minor proteins, or whether the intranuclear pp89 itself is degraded to antigenic peptides presented at the cell membrane in a mode similar to that postulated for influenza A nucleoprotein $(29,30)$, remains to be investigated.

While the presence of a regulatory IE protein during the $\gamma$ phase has been reported for herpes simplex virus type 1 (32), the coincidence of $\alpha$ gene reexpression and presentation of an IE target antigen for CTL during the $\gamma$ phase of MCMV infection is a new finding relevant to immune surveillance.

In a previous communication we postulated sites of preferential IE gene expression to explain the high frequency of IE-specific CTL (24). Since fibroblasts display only class I major histocompatibility antigen, efficient in vivo induction of an IE-specific CTL response also predicts cells that present IE membrane antigen in association with class II major histocompatibility antigen. Recent investigations have identified monocytes and lymphocytes as sites where, in fact, replication of human $\mathrm{CMV}$ is restricted to expression of IE genes (26). Whether these cells also present an IE antigen at the cell membrane and whether CTL that recognize human CMV-infected cells at early times in the replication cycle (1) are directed specifically to an IE membrane antigen await further analysis.

The regulatory function of IE proteins implies that transcription of $\alpha$ genes is a decisive step in virus reactivation from latency. IE antigen-specific memory CTL (23) are candidates to counteract recurrency in its initial phase. At first glance, the finding that CTL effector function appears to be executed mainly during the late phase seems to be inconsistent with that predicted role of CTL. Two arguments, however, have to be considered. First, antigen presentation in permissive fibroblasts infected in vitro is not necessarily representative of other cell types and antigen presentation in vivo. Second, when taking into account the dynamics of the protracted replication cycle of CMVs, the kinetics of IE membrane antigen expression observed in fibroblasts could indeed promote the function of IE-specific CTL. If we speculate that a low level of antigen expression is sufficient for in vivo sensitization of memory CTL already during the IE phase, the generated effector CTL could deliver the lethal hit during the late phase to the same cells by which they have been triggered.

We thank H. Ponta (Kernforschungszentrum Karlsruhe, Karlsruhe, Federal Republic of Germany) for providing transfected L cells, D. Eick (Zentrum für Hygiene, Freiburg, Federal Republic of Germany) for advice, Irene Huber, Anke Lüske, Heidemarie Riehle, and Gabi Röhrs for technical assistance, and Sabine Grau for preparation of the manuscript.

This work was supported by the Deutsche Forschungsgemeinschaft, SFB 120 and Ko571/8.

\section{LITERATURE CITED}

1. Borysiewics, L. K., S. Morris, J. D. Page, and J. E. P. Sissons. 1983. Human cytomegalovirus-specific cytotoxic $\mathrm{T}$ lymphocytes: requirements for in vitro generation and specificity. Eur. J. Immunol. 13:804-809.

2. Brautigam, A. R., F. J. Dutko, L. B. Olding, and M. B. A. Oldstone. 1979. Pathogenesis of murine cytomegalovirus infection: the macrophage as a permissive cell for cytomegalovirus infection, replication and latency. J. Gen. Virol. 44:349-359.

3. Brody, A. R., and J. E. Craighead. 1974. Pathogenesis of pulmonary cytomegalovirus infection in immunosuppressed mice. J. Infect. Dis. 129:677-689.

4. Bukowski, J. F., J. F. Warner, G. Dennert, and R. M. Welsh. 1985. Adoptive transfer studies demonstrating the antiviral effect of natural killer cells in vivo. J. Exp. Med. 161:40-52.

5. Dorsch-Häsler, K., G. M. Keil, F. Weber, M. Jasin, W. Schaffner, and U. H. Koszinowski. 1985. A long and complex enhancer activates transcription of the gene coding for the highly abundant immediate early mRNA in murine cytomegalovirus. Proc. Natl. Acad. Sci. USA 82:8325-8329.

6. Dutko, F. J., and M. B. A. Oldstone. 1981. Cytomegalovirus causes a latent infection in undifferentiated cells and is activated by induction of cell differentiation. J. Exp. Med. 154:1636-1651.

7. Ebeling, A., G. M. Keil, E. Knust, and U. H. Koszinowski. 1983. Molecular cloning and physical mapping of murine cytomegalovirus DNA. J. Virol. 47:421-433.

8. Greenberg, M. E., and E. B. Ziff. 1984. Stimulation of 3T3 cells induces transcription of the c-fos proto-oncogene. Nature (London) 311:433-438.

9. Honess, R. W., and B. Roizman. 1974. Regulation of herpesvirus macromolecular synthesis. I. Cascade regulation of the synthesis of at least three groups of viral proteins. J. Virol. 14:8-19.

10. Jordan, M. C., J. L. Takagi, and J. G. Stevens. 1982. Activation of latent murine cytomegalovirus in vivo and in vitro: a pathogenetic role for acute infection. J. Infect. Dis. 145:699-705.

11. Keil, G. M., A. Ebeling-Keil, and U. H. Koszinowski. 1984. Temporal regulation of murine cytomegalovirus transcription and mapping of viral RNA synthesized at immediate early times after infection. J. Virol. 50:784-795.

12. Keil, G. M., M. R. Fibi, and U. H. Koszinowski. 1985. Characterization of the major immediate-early polypeptides encoded by murine cytomegalovirus. J. Virol. 54:422-428.

13. Kim, K. S., V. J. Sapienza, R. I. Carp, and H. M. Moon. 1976. Analysis of structural proteins of purified murine cytomegalovirus. J. Virol. 17:906-915.

14. Koszinowski, U. H., G. M. Keil, H. Volkmer, M. R. Fibi, A. Ebeling-Keil, and K. Münch. 1986. The 89,000- $M_{\mathrm{r}}$ murine cytomegalovirus immediate-early protein activates gene transcription. J. Virol. 58:59-66.

15. Mayo, D. R., J. A. Armstrong, and M. Ho. 1977. Reactivation of murine cytomegalovirus by cyclophosphamide. Nature (London) 267:721-723.

16. Melton, D. H., P. A. Krieg, M. R. Rebagliati, T. Maniatis, U. Zinn, and M. R. Green. 1984. Efficient in vitro synthesis of biologically active RNA and RNA hybridization probes from plasmids containing a bacteriophage SP6 promoter. Nucleic Acids Res. 12:7035-7056.

17. Meyers, J. D., N. Flournoy, and E. D. Thomas. 1982. Nonbacterial pneumonia after allogeneic marrow transplantation: a review of ten years' experience. Rev. Infect. Dis. 4:1119-1132.

18. O'Connell, K. A., and L. R. Gooding. 1984. Cloned cytotoxic T lymphocytes recognize cells expressing discrete fragments of the SV40 tumor antigen. J. Immunol. 132:953-958.

19. Ponta, H., R. Ball, M. Steinmetz, and B. Groner. 1985. Hormonal regulation of cell surface expression of the major histocompatibility antigen $\mathrm{H}-2 \mathrm{~L}^{\mathrm{d}}$ in transfected cells. EMBO J. 4:3447-3453.

20. Quinnan, G. V., J. E. Manischewitz, and F. A. Ennis. 1978. Cytotoxic $\mathrm{T}$ lymphocyte response to murine cytomegalovirus infection. Nature (London) 273:541-543.

21. Reddehase, M. J., H.-J. Bühring, and U. H. Kosżinowski. 1986. Cloned long-term cytolytic T-lymphocyte line with specificity for an immediate-early membrane antigen of murine cytomegalovirus. J. Virol. 57:408-412.

22. Reddehase, M. J., G. M. Keil, and U. H. Koszinowski. 1984. The cytolytic $\mathrm{T}$ lymphocyte response to the murine cytomegalovirus. I. Distinct maturation stages of cytolytic $\mathrm{T}$ lymphocytes constitute the cellular immune response during acute infection of mice with the murine cytomegalovirus. J. Immunol. 132:432-489.

23. Reddehase, M. J., G. M. Keil, and U. H. Koszinowski. 1984. The cytolytic $\mathrm{T}$ lymphocyte response to the murine cytomegalovirus. II. Detection of virus replication stage-specific antigens by separate populations of in vivo active cytolytic T lymphocyte precursors. Eur. J. Immunol. 14:56-61.

24. Reddehase, M. J., and U. H. Koszinowski. 1984. Significance of herpesvirus immediate early gene expression in cellular immu- 
nity to cytomegalovirus infection. Nature (London) 312: 369-371.

25. Reddehase, M. J., F. Weiland, K. Münch, S. Jonjić, A. Lüske, and U. H. Koszinowski. 1985. Interstitial murine cytomegalovirus pneumonia after irradiation: characterization of cells that limit viral replication during established infection of the lungs. J. Virol. 55:264-273.

26. Rice, G. P. A., R. D. Schrier, and M. B. A. Oldstone. 1984. Cytomegalovirus infects human lymphocytes and monocytes: virus expression is restricted to immediate-early gene products. Proc. Natl. Acad. Sci. USA 81:6134-6138.

27. Shanley, J. D., E. L. Pesanti, and K. M. Nugent. 1982. The pathogenesis of pneumonitis due to murine cytomegalovirus. J. Infect. Dis. 146:388-396.

28. Tevethia, S. S., A. J. Lewis, A. E. Campbell, M. J. Tevethia, and P. W. J. Rigby. 1984. Simian virus 40 specific cytotoxic lymphocyte clones localize two distinct TSTA sites on cells synthesizing a 48 kD SV40 T antigen. Virology 133:443-447.
29. Townsend, A. R. M., F. M. Gotch, and J. Davey. 1985. Cytotoxic $T$ cells recognize fragments of the influenza nucleoprotein. Cell 42:457-467.

30. Townsend, A. R. M., J. Rothbard, F. M. Gotch, G. Bahadur, D. Wraith, and A. J. McMichael. 1986. The epitopes of influenza nucleoprotein recognized by cytotoxic $\mathrm{T}$ lymphocytes can be defined with short synthetic peptides. Cell 44:959-968.

31. Wathen, M. W., and M. F. Stinski. 1982. Temporal patterns of human cytomegalovirus transcription: mapping of the viral RNAs synthesized at immediate early, early, and late times after infection. J. Virol. 41:462-477.

32. Watson, R. J., and J. B. Clements. 1980. A herpes simplex virus type 1 function continuously required for early and late virus RNA synthesis. Nature (London) 285:329-330.

33. Yewdell, J. W., J. R. Bennink, G. L. Smith, and B. Moss. 1985. Influenza A virus nucleoprotein is a major target antigen of cross reactive anti-influenza $\mathrm{A}$ virus cytotoxic $\mathrm{T}$ lymphocytes. Proc. Natl. Acad. Sci. USA 82:1785-1789. 